\title{
Assessment of the Prevalence of Trauma Cases Visited At Emergency OPD in Dilla University Referal Hospital from April 20, 2008-May 20, 2008 E.C
}

\author{
Kaleab Tesfaye Tegegne (BSCPH, MPH)* \\ Department of Public Health, Hawassa College Of Health Science, Hawassa, Ethiopia
}

\section{*Corresponding Author}

Kaleab Tesfaye Tegegne

\section{Article History}

Received: 14.11 .2019

Accepted: 21.11 .2019

Published: 30.11 .2019

\begin{abstract}
Background: Injuries and violence pose a major public health and developmental problem globally. Each year over 5 million people around the world die as a result of injury. Injuries are ranked among the leading cause of death and disability particularly in low income and middle income countries where they are growing insignificance, largely as a consequences of epidemiologic, demographic and socioeconomic transitions. Moreover, it is in these very setting that the vital statistics and routine health information are often seriously lacking. Objective: The objective of this study was to assess the prevalence of trauma cases visited at emergency OPD of DURTH and to describe the magnitude and pattern of injury. Methods: Health institutional based cross sectional study was conducted at emergency OPD from APRIL 20, 2008-MAY 20, 2008 E.C and the data was collected using questionnaires by using convenience sampling technique. All injury cases come to EOPD was studied. A questioner was used to collect the data and the data entered to computer and was analysed by using SPSS version 20. Ethical clearance was obtained from Rift valley University Hawassa campus before the study conducted and the hospital management. Result: 128 patients were visited EOPD of DURH during the study period. The commonest mechanism of injury was RTA, 42(32.8\%), followed by falling related injury and cut by sharp instruments, 22(17.2\%), 20(15.6\%) respectively. More males had RTA, cut and falling related injuries compared to females. The commonest outcomes which resulted in severe injuries were RTA, stab and falling related injuries. Conclusion: The magnitude of injury in the hospital was considerably high. Appropriate prevention strategies should be designed and implemented against RTA, falling related injury and cut by sharp instruments.
\end{abstract}

Keywords: Trauma, suicide, drowning, cases, emergency outpatient department.

\section{INTRODUCTION}

Injuries and violence pose a major public health and developmental problem globally. Each year over 5 million people around the world die as a result of injury. Injuries are ranked among the leading cause of death and disability particularly in low income and middle income countries where they are growing in significance, largely as a consequence of epidemiologic, demographic, and socioeconomic transitions. Moreover, it is in these very setting that the vital statistics and routine health information are often seriously lacking [3].

Globally, injury has been recognized as one of the most life threatening public health problems. Injuries represent $12 \%$ of the global burden of the disease and the third most important cause of overall mortality [4]. Millions have accidents occur each year and thousands of individuals lose their lives. This is well recorded in high income countries [5-7]. It was demonstrated that trauma patients occupied more than $12 \%$ of hospital beds in USA [5] and accounted for more than $50 \%$ of orthopaedic admissions in UK [8]. For each death from injury there are many more injuries that resulted in hospitalization, treatment in the emergency department, treatment by practitioners outside the formal health sector or never received treatment at all.

The world health organization (WHO) global burden of injury estimate ranks injury among the top ten leading cause of death, with an estimated 5 million deaths annually of which men in Africa have the highest injury related mortality rates in the world [9]. Among African nations the rate of injury mortality in 2004 was the highest in Nigeria and the lowest in Egypt. South Africa and Ethiopia

Copyright @ 2019: This is an open-access article distributed under the terms of the Creative Commons Attribution license which permits unrestricted use, distribution, and reproduction in any medium for non commercial use (NonCommercial, or CC-BY-NC) provided the original author and source are credited. 
were second and third respectively [10]. Injury is more common among men and among persons aged 15-44 years [11]. Injury deaths attributable to road traffic crashes was the highest in Egypt (41\%) followed by Ethiopia (30\%) [10].

Each year, over 310,000 deaths occur due to fire related burns in the world [12]. Children ages 1-9 years are more vulnerable to fire related deaths than older children and adults [13]. On the other hand, regardless of age, fall related injuries account for more than half of non fatal injuries resulting in extensive health care utilization and protracted period of sick days with profound economic impact $[14,15]$.

In Ethiopia, there are very limited data on injury. Some institutions based studies conducted in different parts of the country. However it shows that injury is a public health problem that results in morbidity, mortality and disability. A study conducted in North Gondar in 2000 rivalled that $5.4 \%$ of the total patients seen in health institutions were injury cases and the leading cause of injury were assault (48.5\%), fall (18.6\%) and road traffic (14.7\%) [16]. The study may provide important information for the responsible body to adjust the emergency care to trauma victims so as to reduce the immediate and long stand impact of the problem.

\section{SubJeCtS And Methods \\ Study Area and Period}

The study was conducted in DURH.DURH was first established as a clinic in 1920 E.C which latter in 1950 E.C upgraded to hospital and named as Leul Mekonen. In 1977 E.C. The hospital was upgraded to give service for 250,000 people bring the name Dilla district hospital and called DURTH. Currently it provide service for about 2 million catchment population with a total capacity of about 108 beds and it has 113 nurses (19 midwife), 83 general practitioners and 4 seniors. It provide range of service in outpatient (2576/month), in patient and emergency basis (625/month) in various areas; namely internal medicine, paediatrics, obstetrics and Gynaecology, surgery, dentistry, ophthalmology and psychiatry.

The study was conducted from APRIL 20, 2008-MAY 20, 2008 E.C

\section{Study Design}

Institution based cross sectional study was conducted at emergency outpatient department of Dilla university referral hospital from APRIL 20, 2008-MAY 20, 2008 E.C.

\section{Study Population}

All the patients who visited the emergency OPD of DURTH due to injury during the study period Inclusion and Exclusion criteria.

\section{Inclusion Criteria}

- All patients visited at emergency OPD due to injuries on the study time.

\section{Exclusion Criteria}

- Those patients who come to emergency OPD because of medical cases.

- Those who are severely injured and cannot respond and not able to hear, speak and those who mentally ill Cases that die before they reach the hospital or minor cases that sought care at other facilities.

- Those patients who referred and visit to these hospital but are out of the catchment of DURTH.

\section{Sample Size and Sampling Technique} University.

The sample size was determined by using a single population proportion formula by assuming study done on Jimma

$$
\mathrm{N}=Z 2 \mathrm{P}(1-\mathrm{P}) / \mathrm{D} 2 \quad(1.96)(1.96) 0.082(1-0.082) /(0.05)(0.05)=116
$$

Where $n=$ numbered required

$\mathrm{z}=$ critical value $(1.96)$

$\mathrm{p}=$ prevalence $(8.2 \%$ according to the study conducted in Jimma university, 2014)

$D=$ margin of error $(5 \%)$. and by adding $10 \%$ of non response rate the sample will be 128

Convenience non-probability sampling technique was used to collect the data.

\section{Data Collection Procedures}

Data was collected using questionnaires the socio demographic characteristics and characteristics of injury i.e. mechanism, place of injury, activity at the time of injury, site and degree (severity) of injury and outcomes will be collected by questionnaires.

Data was collected by investigator at emergency OPD on their respective days. The investigator was trained how to collect this particular questioner and the data collection process was supervised closely by the investigator. 


\section{Data Quality Assurance}

All Group members of research were undertake data collection .Before the actual data collection, the questionnaire was pre tested in $5 \%$ of population in yirgalem referal hospital Based on the pretest, necessary modification were made on the questions and the data of the pretest was excluded in the actual data analysis

To keep the data as accurate as possible, the structured check list for data collection was used thoroughly throughout the process. Completeness of the data and possible errors was also be monitored carefully.

\section{Data Processing and Analysis}

After the data was collected the frequency distribution of dependent and independent variables was organized using frequency table, graph, and chart. Chi-square was used to determine the associations between the selected variables. $P$-value also was calculated in order to identify possible statistically significant risk factors.

\section{Ethical Considerations}

Ethical clearance was obtained from research and ethical committee (REC) of rift valley University, department of public health. Permission for conducting the study were obtained from Dilla university referral hospital. In addition written informed consent was obtained from the study participant before data collection and the patient name was not be recorded on the questionnaire to grant confidentially of the information.

\section{Results}

One hundred twenty eight injury cases were visited at EOPD of DURH during one month's period from April 20-May 20, 2008 E.C. and all visited cases analyzed in the study. From the injury cases visited $74(57.8 \%)$ were males and $54(42.2 \%)$ were females. $100(78.1 \%)$ Of cases were $15-49$ years old, $14(10.9 \%)$ were $5-14$ years old, $2(1.6 \%)$ were $>65$ years, and $12(9.4 \%)$ were 50 65 years old.

The educational status of the cases were 36(28.1\%), 30(23.4\%), 29(22.7\&), \&33(25.8\%) were illiterate, elementary school, secondary school and above and read and write only respectively. From the injury cases visited at EOPD on the study time $62(48.4 \%)$ were protestants, $43(33.6 \%)$ were orthodox, and $21(16.4 \%)$ were Muslim and 2(1.6\%) were others. The occupational status of the cases majority cases were students which was $32(25 \%)$ and $29(22.7 \%), 16(12.5 \%), 13(10.2 \%)$ were farmers, private business, and daily labourer respectively. Majority of cases married $67(52.3 \%)$ and the rests were unmarried $50(39.1 \%) \& 11(8.6 \%)$ windowed (See Table $1 \mathrm{a}$ and $\mathrm{b}$ ).

Table-1a: Socio-demographic characteristics of injury cases who visited EOPD OF DURH from April 20-May 20, 2008 E.C

\begin{tabular}{|l|l|l|}
\hline Variable & Frequency & Percent (\%) \\
\hline Sex $(\mathbf{n}=\mathbf{1 2 8})$ & & \\
Male & 74 & 57.8 \\
Female & 54 & 42.2 \\
\hline Age(n=128) & & \\
$5-14$ & 14 & 10.9 \\
$15-49$ & 100 & 78.1 \\
$50-65$ & 12 & 9.4 \\
$>65$ & 2 & 1.6 \\
\hline Educational status (n=128) & 29 & 22.7 \\
High school and above Elementary school & 30 & 23.4 \\
Read and write only & 33 & 25.8 \\
Illiterate & 36 & 28.1 \\
\hline
\end{tabular}


Table-1b: Socio-demographic characteristics of injury cases who visited EOPD OF DURH from April 20-May 20, 2008 E.C

\begin{tabular}{|l|l|l|}
\hline Variable & Frequency & Percent (\%) \\
\hline Marital status(n=128) & & \\
$\quad$ Married & 67 & 52.3 \\
$\quad$ Unmarried & 50 & 39.1 \\
$\quad$ Widowed & 11 & 8.6 \\
\hline Occupational status(n=128) & & \\
Farmer & 29 & 22.7 \\
Student & 32 & 25.0 \\
House wife & 29 & 22.7 \\
Unemployed & 4 & 3.1 \\
Private business & 16 & 12.5 \\
Civil servant & 2 & 1.6 \\
Daily laborer & 13 & 10.2 \\
Retired & 2 & 1.6 \\
Others & 1 & 0.8 \\
\hline Religion(n=128) & & \\
Protestant & 62 & 48.4 \\
Orthodox & 43 & 33.6 \\
Muslim & 21 & 16.4 \\
Others & 2 & 1.6 \\
\hline
\end{tabular}

Result on the intent of injury showed that $4(3.1 \%)$ were injured intentionally and $124(96.9 \%)$ were injured unintentionally (See Table-2).

Table-2: Intent of injury who visited EOPD OF DURH from April 20- May 20, 2008 E.C

\begin{tabular}{|l|l|l|}
\hline Intent of injury & Frequency & Percent (\%) \\
\hline Intentional & 4 & 3.1 \\
\hline Unintentional & 124 & 96.9 \\
\hline
\end{tabular}

The commonest mechanism of injury was RTA; 42(32.8\%), followed by falling related injury $22(17.2 \%)$, cut by sharp instruments 20(15.6\%), fire related burns $10(7.8 \%)$, firearm $8(6.3 \%)$, stab $7(5.5 \%)$ and others 2(1.6\%) (See Table-3).

Table-3: Mechanism of injury

\begin{tabular}{|l|l|l|}
\hline Mechanism of injury & Frequency & Percent (\%) \\
\hline Cut by sharp instruments & 20 & 15.6 \\
\hline Falling related accidents & 22 & 17.2 \\
\hline Stab injury & 7 & 5.5 \\
\hline Bitten by animals & 5 & 3.9 \\
\hline Fire related burns & 10 & 7.8 \\
\hline Burn due to boiled water oil & 8 & 6.3 \\
\hline RTA & 42 & 32.8 \\
\hline Poisoning & 2 & 1.6 \\
\hline Suicide & 2 & 1.6 \\
\hline Firearm & 8 & 6.3 \\
\hline Others & 2 & 1.6 \\
\hline
\end{tabular}

Out of the 128 cases visited at the EOPD of DURH, 41(32\%), 34(26.6\%), 15(11.7\%), 11(8.6\%) took place on the road, inside home, on the job, and around home respectively (See Table-4).

Table-4: Place of injury

\begin{tabular}{|l|l|l|}
\hline Place of injury & Frequency & Percent (\%) \\
\hline Around home & 11 & 8.6 \\
\hline Inside home & 34 & 26.6 \\
\hline Farming place & 9 & 7.0 \\
\hline On the job & 15 & 11.7 \\
\hline On the road & 41 & 32.0 \\
\hline In the school & 4 & 3.1 \\
\hline Other places & 8 & 6.3 \\
\hline
\end{tabular}


From the injury cases on the study time $28(21.9 \%)$ sustained on only the upper extremity followed by $23(18 \%)$ on the lower extremity (See Table-5).

Table-5: Body affected by injury

\begin{tabular}{|l|l|l|}
\hline Body affected by injury & Frequency & Percent (\%) \\
\hline Only head & 21 & 16.4 \\
\hline Head and neck & 9 & 7.0 \\
\hline Thorax and abdomen & 11 & 8.6 \\
\hline Back & 13 & 10.2 \\
\hline Both upper and lower extremities & 17 & 13.3 \\
\hline Only upper extremity & 28 & 21.9 \\
\hline Only lower extremity & 23 & 18.0 \\
\hline Groin and genitals & 2 & 1.6 \\
\hline Others & 4 & 3.1 \\
\hline
\end{tabular}

From the 128 cases managed as an outpatient $77(60.2 \%)$ were treated and discharged as an outpatient, $10(7.8 \%)$ were referred immediately for further management (See Table-6).

Table-6: Outcome of the patient from injury cases

\begin{tabular}{|l|l|l|}
\hline Outcome of patients & Frequency & Percent (\%) \\
\hline Treated and discharged as an outpatient & 77 & 60.2 \\
\hline Referred immediately for further management & 10 & 7.8 \\
\hline Died Immediately & 3 & 2.3 \\
\hline Others & 38 & 29.7 \\
\hline
\end{tabular}

With regard to injury spectrum $29(22.7 \%)$ were classified as sever, $35(27.3 \%)$ were moderate and the rest $64(50.0 \%)$ were classified as minor injury (See Table-7).

Table-7: Severity of injury

\begin{tabular}{|l|l|l|}
\hline Severity of injury & Frequency & Percent (\%) \\
\hline Minor & 64 & 50.0 \\
\hline Moderate & 35 & 27.3 \\
\hline Severe & 29 & 22.7 \\
\hline
\end{tabular}

\section{Discussion AND CONCLUSION}

The study revealed magnitude of injury In DURH to be $0.256 \%$. This is relatively lower when compared to a study conducted in North Gondar zone in 2000 using twenty institutions which revealed a magnitude of 5.4\% [16]. The magnitude is lower than a study of total surgical admission $(5,907)$ to the rift valley provincial general hospital of Kenya in 2002 where $3411(57.7 \%)$ were trauma cases [56]. Similarly, another study at Viet Duc hospital in 2006 had reported a higher magnitude with 17,643 injury cases treated in emergency department, representing $70 \%$ of all emergencies [58]. The time of investigation and differences in the level and number of facilities studied could partly explain this difference. The injured cases were predominantly males which are consistent with other similar studies [16-46, 59] and most of injuries involved people aged 15-49 years. This pattern remained the same for most injury mechanisms and outcomes. This is also an agreement with other similar studies [53, 46, 59]. It is expected that people in this age group tend to live a more active life than other age group [58]. Obviously, this would signify a resultant economic impact and loss in productive years of life [15].

The study revealed that $3.1 \%$ of the injuries were intentional and is lower than $23 \%$ reported from Tikur Anbessa hospital, Addis Ababa [46] and 8\% from Vietnamese hospital [58]. However, another study conducted in Canadian hospitals reported more intentional injuries. The possible explanation for the variation may be the difference in study time and setting. The commonest mechanisms of injury were RTA and falling related followed by cut by sharp instruments. Similarly, studies conducted in Tikur Anbessa, Addis Ababa [46], in North Gondar zone [16] and in rift valley provincial general hospital of Kenya [56] had reported same trend with RTA at top followed by interpersonal assault and accidental fall. However, another study conducted in St Paul's hospital, Addis Ababa, eldort, Kenya, assaults were the leading cause for injury [15].

Females, as compared to males, were almost twice more likely to have had cut injuries by sharp instruments. Studies from western Kenya [58] and Ghana reported the same observation. Similarly, males were less likely to have had burn which is consistent with other studies $[15,59]$. This may be attributed to the high exposure women have due to their role in domestic activities such as cooking, baking, and ironing [15]. Moreover, males were more likely to have had RTA. This is partly supported by the study conducted in Ghana were males predominated in all mechanisms of injury. This study also showed that cut and assault injury was higher among 
age group 15-49 and 50-64 years compared to 0-4 years. Similarly, the study from Ghana reported that assault was more common in 15-34 and 35-59 years than 0-4 years. The two most common places of injury were road and home. Another study in the same zone however reported that more than $2 / 3$ of injuries occurred in and around home environment and funning places [53]. On the other hand higher prevalence of injuries from road accidents were observed in the hospital for it serves as a referral centre not only for Dilla zone but also for other adjacent zones and as well the injuries might be more serious in nature. The three leading outcomes of injuries were bruise or skin laceration, fracture and internal organ injury and this is a different pattern as compared to various studies. Cut or bite wound, sprain, bruise, fracture, and internal organ injury were reported to be the commonest outcomes in the community based study [53]. In a Kenyan hospital study, the most common injuries were fractures, burn, soft tissue and head injuries [56]. In another Nigerian teaching hospital study, lacerations and fractures represented most of injuries. Possibly, differences in the definition of what a "case" means in the studies being compared might have also contributed to the variation. Fracture cases were more frequent in 50-64 \& 64 years old and above and this is consistent with other report [59].

In conclusion, the magnitude of injury in the hospital was considerably high with more unintentional injuries; predominantly involving males, people aged 15-49 years, farmers and students. RTA, cut by sharp tool and falling were the commonest mechanisms. The commonest places of injury were on the road, around and in home. RTA, falling related injury and cut by sharp tool resulted in more severe injuries.

\section{ACKNOWLEDGMENT}

I would like to express my gratitude to all data collectors for their unreserved help and facilitation. My heartfelt thanks also goes to Rift valley University for giving me this chance to do this research work. Finally, I am greatly indebted to my wife Netsanet Desalegne she gave me courage deserves my utmost gratitude for helping me to do this Research work

\section{REFERENCES}

1. Baker, S. P., O'Neill, B., \& Karpf, R. S. (1984). The injury fact book. Lexington, MA. Lexington books.

2. World Health Organization. (2002). The injury chart book a graphical over view of the global burden of injuries Department of injuries and violence prevention Non-communicable diseases and mental health cluster Geneva.

3. Krug, E. G., Sharma, G. K., \& Lozano, R. (2000). The global burden of injuries. American journal of public health, 90(4), 523526.

4. World health report 2001. (2001). Mental Health: New understanding, new hope. Geneva, WHO

5. Marc, E., Mitchell, J. A. (1995). Gris world. Management of multiple traumas. Wallace P. Ritchie, Glenn Steele. Richard, H. Dean eds. General surgery. Philadelphia, J. B Lippincott company; 919-928.

6. Haas, N. P. (2002). The trauma centre: now and in the future. The Journal of bone and joint surgery. British volume, 84(5), 627630.

7. Court-Brown, C., \& McQueen, M. M. (1997). Trauma management in the United Kingdom. Journal Bone Joint Surgery, 97$B(1): 1-3$.

8. Alpart, E. K., Bull. J., \& Court-Brown, M. (1997). Corresponding trauma management. Journal Bone Joint Surgery,79-B(6):10381039

9. World Health Organization. (2002). Author the injury record book: a graphical over view of the global burden injuries. httphttp:/whqlibdoc.WHO.tnt/publications/924156220X.pdf.

10. World Health Organization. (2004). Author measurement and health information data sheet. Geneva. Sweezerland: WHO.

11. Krug, E. (1999). Injury: a leading cause of the global burden of disease. Geneva: WHO. available on internet at: WWW.WHO.int/violence injury prevention.

12. Karrer, M. J. (2007). Fire loss in the united states during 2006.quiney (MA): national fire protection association, fire analysis and research division.

13. Sellassie, A. W. (2008). Invited commentary; the management of epilepsy in sub-Saharan Africa, 49(9):644-646.

14. Injury pyramid. Geneva: WHO; available on the internet: at.WWW.WHO.INT/violence injury prevention. last updated 2001.

15. Gebeyahu, K., \& Mehari, E. (2009). Injury Prevention. Public Health Information, 2:1-23.

16. Osman, M., Kebede, Y., \& Anberbir, S. (2003). Magnitude and pattern of injuries in north Gondar administrative zone, northwest Ethiopia. Ethiopian medical journal, 41(3), 213-220.

17. World Health Organization. (1992). International statistical classification of diseases and related health problems, tenth revision. Volume 1; tabular list. Geneva.

18. World Health Organization. (2002). The injury chart book a graphical over view of the global burden of injuries. Department of injuries and violence prevention.non communicable diseases and mental health cluster Geneva, 19-26.

19. Adapted from: a simple guide to burn treatment. A project of the international society for burn injuries in collaboration with the WHO. June 1994

20. World Health Organization. (2002). The injury chart book. A graphical overview of the global burden of injuries. Department of injuries and violence prevention of non communicable diseases and mental health cluster Geneva, 27-34.

21. World Health Organization. (1992). International statistical classification of diseases and related health problems: 10th revision (ICD-10). http://www. who. int/classifications/apps/icd/icd. 
22. World Health Organization. (2002). The injury chart book. A graphical overview of the global burden of injuries. Department of injuries and violence prevention Noncommunicable diseases and mental health cluster Geneva, 35-42.

23. World Health Organization. (1992). International statstical classification of diseases and related health problems, tenth revision, volume 1: Tabular list. Geneva.

24. World Health Organization. (2002). The Injury Chart Book A graphical overview of the global burden injuries. Department of injuries and violence prevention Noncommunicable diseases and mental health cluster, Geneva, 43-50.

25. World Health Organization. (1992). International statsistical classification of diseases and related health problems, tenth revision, volume 1: Tabular list. Geneva.

26. World Health Organization. (2002). The injury chart book. A graphical overview of the global burden of injuries. Department of injuries and violence prevention noncommunicable diseases and mental health cluster Geneva, 51-58.

27. Violence: a public health priority. (1996). Geneva,WHO, (document EHA/SPI/POA).

28. World Health Organization. (2002). The injury chart book. A graphical overvier of the global burden of injuries. Department of injuries and violence prevention noncommunicable disease and mental health cluster Geneva, 59-66.

29. Rosenberg, M. L., Davidson, L. E., Smith, J. C., Berman, A. L., Buzbee, H., Gantner, G., ... \& O'carroll, P. W. (1988). Operational criteria for the determination of suicide. Journal of Forensic Science, 33(6), 1445-1456.

30. World Health Organization. (2002). The injury chart book. A graphical overview of the global burden of injuries. Department of injuries and violence prevention noncommunicable diseases and mental health cluster. Geneva, 65-75.

31. Deen, J. L., Vos, T., Huttly, S. R., \& Tulloch, J. (1999). Injuries and noncommunicable diseases: emerging health problems of children in developing countries. Bulletin of the World Health Organization, 77(6):518-524.

32. Krug, E. G., \& World Health Organization. (1999). Injury: a leading cause of the global burden of disease (No. WHO/HSC/PVI/99.11). Geneva: World Health Organization.

33. Nordberg, E. (2000). Injuries as a public health problem in sub-Saharan Africa: epidemiology and prospects for control. East African medical journal, $77(12$ Suppl), S1-43.

34. WHO. (2006). Regional office for Africa. The health of the people; the African health report.

35. Berhane, Y., Mariam, D. H., \& Klous, H. (2005). The epidemiologic and ecology of health and disease in Ethiopia.

36. Nordberg, E. (1994). Injuries in Africa: a review. East African Medical Journal, 71(6), 339-345.

37. van Ginneken, J. K., \& Voorhoeve, A. M. (1990). Mortality by cause of death in a rural area of Machakos District, Kenya in 197578. Journal of biosocial science, 22(1), 63-75.

38. Ad Hoc Committee on Health Research Relating to Future Intervention Options, \& World Health Organization. (1996). Investing in Health Research and Development: Report of the Ad Hoc Committee on Health Research Relating to Future Intervention Options, Convened Under the Auspices of the World Health Organization (Vol. 96). World Health Organization.

39. Smith, G. S., \& Barss, P. (1991). Unintentional injuries in developing countries: the epidemiology of a neglected problem. Epidemiologic reviews, 13(1), 228-266.

40. Forjuoh, S. N., \& Gyebi-Ofosu, E. (1993). Injury surveillance: should it be a concern to developing countries?. Journal of public health policy, 14(3), 355-359.

41. Kobusingye, O., Guwatudde, D., \& Lett, R. (2001). Injury patterns in rural and urban Uganda. Injury prevention, 7(1), 46-50.

42. Kobusingye, O. C., Guwatudde, D., Owor, G., \& Lett, R. R. (2002). Citywide trauma experience in Kampala, Uganda: a call for intervention. Injury Prevention, 8(2), 133-136.

43. Mock, C. N., Abantanga, F., Cummings, P., \& Koepsell, T. D. (1999). Incidence and outcome of injury in Ghana: a communitybased survey. Bulletin of the World Health Organization, 77(12), 955-964.

44. Taye, M., \& Munie, T. (2003). Trauma registry in Tikur Anbessa Hospital, Addis Ababa, Ethiopia. Ethiopian medical journal, 41(3), 221-226.

45. Gedlu, E. (1994). Accidental injuries among children in north-west Ethiopia. East African medical journal, 71(12), 807-810.

46. Daniel, E., \& Yoo, M. C. (1990). Survey of burn admissions to Ethio Swidish childrens hospital. Ethiopia medical Journal, 28:163168

47. Courtright, P., Haile, D., \& Kohls, E. (1993). The epidemiology of burns in rural Ethiopia. Journal of Epidemiology \& Community Health, 47(1), 19-22.

48. Ketsela, T., \& Kebede, D. (1997). Physical punishment of elementary school children in urban and rural communities in Ethiopia. Ethiopian medical journal, 35(1), 23-33.

49. Deyessa, N., Kassaye, M., Demeke, B., \& Taffa, N. (1998). Magnitude, type and outcomes of physical violence against married women in Butajira, southern Ethiopia. Ethiopian medical journal, 36(2), 83-92.

50. Osman, M., Kebede, Y., \& Anberbir, S. (2003). Magnitude and pattern of injuries in north Gondar administrative zone, northwest Ethiopia. Ethiopian medical journal, 41(3), 213-220.

51. Woldemichael, K., Tessema, F., Sena, L., Sofonias, G., \& Abdella, K. (2008). Community based survey of injury in Jimma zone, southwest Ethiopia. Ethiopian journal of health sciences, 17(4), 179-88.

52. Odero, W. O., \& Kibosia, J. C. (1995). Incidence and characteristics of injuries in Eldoret, Kenya. East African medical journal, 72(11), 706-710.

53. Taye, M., \& Munie, T. (2003). Trauma registry in Tikur Anbessa Hospital, Addis Ababa, Ethiopia. Ethiopian medical journal, 41(3), 221-226. 
54. Masiira-Mukasa, N., \& Ombito, B. R. (2002). Surgical admissions to the rift valley provincial general hospital, Kenya. East African medical journal, 79(7), 373-378.

55. Injury pyramid. (2001). Geneva: WHO; available on the internet at www.WHO.int/violence injury prevention last updated.

56. Nguyen, D., Cao, D., \& Nguyen, D. H. (2007). Preliminary results of injury surveillance at Viet Due hospital. The Thai Journal of Surgery, 28:83-89.

57. Odero, W. O., \& Kibosia, J. C. (2007). Incidence and characterestics of injuries presenting to a rural health centers in Western Kenya. East Afican Medical Journal, 84(8):367-368.

58. Pickett, W., Hartling, L., \& Brison, R. J. (1997). A population-based study of hospitalized injuries in Kingston, Ontario, identified via the Canadian Hospitals Injury Reporting and Prevention Program. Chronic Diseases and Injuries in Canada, 18(2), 1A.

59. Mock, C. N., Adzotor, E., Denno, D., Conklin, E., \& Rivara, F. (1995). Admissions for injury at a rural hospital in Ghana: implications for prevention in the developing world. American Journal of Public Health, 85(7), 927-931. 